\title{
L'assimilació dels llibres sobre els animals d'Aristòtil en la medicina d'Arnau de Vilanova (c. 1240-1311)
}

\section{Sergi Grau Torras (*)}

$\left(^{*}\right) \quad$ orcid.org/0000-0003-4730-0812. Institut d'Estudis Medievals, Universitat Autònoma de Barcelona.sergigrautorras@gmail.com

Dynamis

[0211-9536] 2015; 35 (1): 35-55

http://dx.doi.org/10.4321/S0211-95362015000100002
Fecha de recepción: 29 de julio de 2013

Fecha de aceptación: 24 de marzo de 2014

SUMARI: 1.-Introducció. 2.-Les traduccions llatines dels llibres sobre els animals durant els segles XII i XIII. 3.-Els Ilibres sobre els animals i la Facultat de Medicina de Montpeller durant la segona meitat del segle XIII. 4.-El cor i el moviment dels animals. 5.-El cor com a principi de generació. 6.—La generació dels animals: humitat radical i humitat espermàtica. 7.—Conclusions.

RESUM: La traducció llatina dels llibres sobre els animals d'Aristòtil que es va dur a terme durant l'edat mitjana, va comportar la difusió de noves teories de l'àmbit de la biologia i zoologia a la cultura occidental. A partir de la segona meitat del segle XIII, aquest conjunt de llibres va contribuir al desenvolupament d'una nova pràctica mèdica fonamentada en la recuperació dels clàssics i la filosofia natural. Arnau de Vilanova (c. 1240-1311), un dels metges més importants de l'edat mitjana llatina, va utilitzar en diverses ocasions el conjunt de llibres sobre els animals per descriure processos biològics i fisiològics i formular una nova disciplina mèdica en el marc de les discussions entre la filosofia natural i la medicina de Montpeller de finals del segle XIII i principis del XIV.

PARAULES CLAU: Arnau de Vilanova, Aristòtil, filosofia natural, medicina, Montpeller.

KEY WORDS: Arnau de Vilanova, Aristotle, natural philosophy, medicine, Montpellier. 


\section{Introducció $(*)$}

El conjunt de traduccions llatines ${ }^{1}$ que es va dur a terme durant l'edat mitjana va ser de gran importància per al desenvolupament de la cultura Occidental ${ }^{2}$. Un dels autors grecs que va rebre més atenció va ser Aristòtil. La traducció llatina de les seves obres va contribuir a transformar progressivament la visió del món i de la natura. Al llarg del segle XIII, gran part del corpus aristotèlic va quedar establert en el currículum de les universitats; per una banda l'Organon, o els llibres introductoris de lògica com els Tòpics, Categories i els Analitics, els quals van esdevenir matèria d'estudi en les facultats d'arts des de les primeres dècades del segle XIII, i per l'altra, la filosofia natural amb els libri naturales d'Aristòtil juntament amb els llibres De anima i la Metafísica. L'assimilació de la filosofia natural va ser gradual, i en certs casos va sofrir una forta oposició, especialment a la universitat de París a partir de 1215. Tot i això, els llibres de filosofia natural van continuar en l'ensenyança universitària fins a la seva definitiva consolidació a finals de segle. A més, la implementació de la filosofia natural aristotèlica en la universitat va tenir repercussió en disciplines com la medicina i va

(*) Aquest treball s'ha pogut realitzar gràcies al projecte de recerca del Ministerio de Economía y Competitividad FFI2011-29117-C02-02 «Corpus digital de la ciencia medieval en la corona de Aragón y su contexto latino y románico: obras vernáculas, Arnau de Vilanova y Vicent Ferrer. 02. Arnau de Vilanova».

1. Abreviatures: Arnaldi de Villanova Opera Medica Omnia (AVOMO), Aristoteles Latinus (AL), Aristoteles Latinus Database. Release 2/2006, moderantibus J. Brams, C. Steel, P. Tombeur, cooperantibus P. De Leemans et E. Gouder. Turnhout: Brepols (ALD) i Aristoteles Semitico-Latinus (ASL). Les referències als textos d'Aristòtil s'han dut a terme en base a la numeració d'Immanuel Bekker (Immanuel Bekker. Aristotelis Opera edidit Academia Regia Borussica. Berlín; 1831-1870). Quan proporcionem el text llatí d'Aristòtil, després de la numeració de Bekker, anotem entre parèntesi el traductor i la referència bibliogràfica amb l'abreviatura de la colllecció a la que pertany l'edició.

2. Actualment hi ha una important producció bibliogràfica en relació a la recuperació del corpus aristotèlic. A títol general remetem el lector a les introduccions que precedeixen les edicions de les col.leccions AL i ASL en les quals es pot trobar una anàlisi exhaustiva de les obres que han estat editades críticament amb la bibliografia corresponent i l'estudi codicològic. Sobre el projecte AL vegeu a títol introductori: Dod, Bernard G. Aristoteles Latinus. In: Kretzmann, Norman; Kenny, Anthony; Pinborg, Jan, eds. The Cambridge History of later medieval philosophy from the rediscovery of Aristotle to the disintegration of scholasticism 11001600. Cambridge: Cambridge University Press; 1982, p. 45-79; Brams, Josef. La riscoperta di Aristotele in occidente. Milano: Jaca Book; 2003. 
contribuir al desenvolupament d'una nova pràctica mèdica fonamentada en la recuperació dels metges clàssics i la filosofia natural d'Aristòtil ${ }^{3}$.

De tot el conjunt d'obres d'Aristòtil que formen part de la filosofia natural, podem destacar la colllecció de llibres sobre els animals. Aristòtil va aglutinar en 5 llibres de llargària diversa i contingut variat els seus estudis i investigacions sobre el món animal i els processos biològics que se'n deriven ${ }^{4}$. La temàtica d'aquests escrits enllaça amb el conjunt breu de tractats de filosofia natural conegut com els Parva naturalia i el De anima ${ }^{5}$. Els llibres sobre els animals van ser traduits al llatí i comentats per autors diversos i van donar lloc a una important producció literària en diferents camps del saber ${ }^{6}$. La seva traducció també va ser de gran importància per a la configuració de la nova medicina durant l'edat mitjana, sobretot per a la teorització dels processos biològics i fisiològics dels éssers vius. A partir de la primera meitat del segle XIII, són diversos els metges que utilitzen un ampli ventall d'obres d'Aristòtil en els seus escrits, entre les quals es troben els llibres sobre els animals?

3. Sobre la construcció d'aquest nou model mèdic vegeu McVaugh, Michael R. The nature and limits of medical certitude at early fourteenth-century Montpellier. Osiris. 1990; 6: 62-84; García Ballester, Luis. The construction of a new form of learning and practicing medicine in medieval Latin Europe. Science in context. 1995; 8: 75-102.

4. Sobre la importància dels escrits de biologia i zoologia d'Aristòtil vegeu a títol general: Joly, Robert. La biologie d'Aristote. Revue Philosophique de la France et de l'Étranger. 1968; 158: 219-253; Preus, Anthony. Science and philosophy in Aristotle's biological works. Hildesheim - New York: Georg Olms; 1975; Byl, Simon. Recherches sur les grands traités biologiques d'Aristote: Sources écrites et préjugés. Brussels: Académie Royale de Belgique; 1975; Gotthelf, Allan; Lennox, James G. eds. Philosophical issues in Aristotle's biology. Cambridge: Cambridge University Press; 1987; Lennox, James G. Aristotle's philosophy of biology. Studies in the origins of life science. Cambridge: Cambridge University Press; 2001.

5. Federici Vescovini, Graziella. La tradizione dei Parva Naturalia nell'insegnamento universitario medievale (secoli XIII e XIV). In: Crisciani, Chiara; Lambertini, Roberto; Martorelli Vico, Romana, eds. Parva naturalia: saperi medievali, natura e vita; atti dell'XI convegno della Società Italiana per lo Studio del Pensiero Medievale, Macerata, 7 - 9 dicembre 2001 (Pubblicazioni della Facoltà di lettere e filosofia, Università di Macerata, Atti di convegni, 44) Pisa: Istituti editoriali e poligrafici internazionali; 2004, p. 125-141.

6. Vegeu Van den Abeele, Baudouin. Le De animalibus d'Aristote dans le monde latin: modalités de sa réception médiévale. Frühmittelalterliche Studien. 1999; 33: 287-318; Perfetti, Stefano. I libri De animalibus di Aristotele e i saperi sugli animali nel XIII secolo. In: Crisciani, n. 5, p. 143-170.

7. Sobre aquest assumpte vegeu Birkenmajer, Alexander. Le rôle joué par les médecins et les naturalistes dans la réception d'Aristote aux XIle et XIIle siècles. Études d'histoire des sciences et de la philosophie du Moyen Âge (Studia Copernicana, 1). Wroclaw - Varsaw - Kraków: Zaklad Narodowy Imienia Ossolinskich; 1970: 73-87. 
Arnau de Vilanova (c. 1240-1311), un dels metges més importants i de més prestigi de l'edat mitjana llatina, ha llegat una extensa obra mèdica en llatí que va contribuir, en gran mesura, a definir la medicina com una ciència en el sentit escolàstic d'aquest terme. Arnau va estudiar medicina a la Universitat de Montpeller cap al 1260, una data en la qual ja estaven disponibles diverses traduccions llatines dels llibres sobre els animals, juntament amb un gran nombre de comentaris. Arnau de Vilanova va emprar els llibres sobre els animals de forma directa en un mínim de quatre obres.

La primera vegada que Arnau en va fer referència va ser al voltant de 1270 en el Tractatus de amore heroico per incidir en la importància del cor en el moviment dels animals. No fou fins la seva etapa com a professor a la Facultat de medicina de Montpeller a partir de 1290 fins el 1301 que els va utilitzar de forma més abundant en les discussions mèdiques del moment. En el Tractatus de consideracionibus operis medicine (c. 1298-1300), Arnau va tornar a referir-se a la mateixa qüestió plantejada anteriorment però de forma diferent. En el Tractatus de intentione medicorum (c. 1290), un escrit elaborat per conjugar les discrepàncies entre el metge Galè i Aristòtil, Arnau menciona el De partibus animalium, i en un altra obra centrada en l'humit radical, el Tractatus de humido radicali (c. 1295-1300), Arnau utilitza el De historia animalium i el De generatione animalium.

En aquesta darrera obra també constatem alguns parallelismes amb altres metges i professors de la Facultat de medicina de Montpeller, com és el cas de Bernard de Gordon (c. 1258-1318/20) amb el Tractatus de marasmode secundum intencionem Galieni (c. 1305), un text coetani d'Arnau sobre el marasme de Galè, la humitat radical i la llarga vida. En aquest tractat, Bernard de Gordon utilitza els mateixos llibres que Arnau en relació a l'humit radical, com són el De historia animalium i el De generatione animalium, per abordar qüestions similars. Així, doncs, la implementació del conjunt de llibres sobre els animals d'Aristòtil en la medicina arnaldiana es va dur a terme en el context de Montpeller i de forma similar a com ho van fer altres metges. En aquest article ens proposem presentar, en primer lloc, el rerefons cultural de la Universitat de Montpeller, que permet la progressiva assimilació d'aquests llibres durant la segona meitat del segle XIII, un context en el qual situem la formació acadèmica d'Arnau de Vilanova. I en segon lloc, ens proposem analitzar l'assimilació i la implementació de les teories que provenen dels llibres sobre els animals en les obres mèdiques d'Arnau de Vilanova i el context en el que foren desenvolupades. 


\section{Les traduccions llatines dels llibres sobre els animals durant els segles XII i XIII}

El conjunt de llibres que formen els escrits sobre els animals d'Aristòtil van arribar a Occident a través de traduccions llatines que provenien de l'àrab i del grec. La primera versió llatina difosa fou realitzada per Michael Scot des de l'àrab a Toledo al voltant de $1220^{8}$. Aquesta versió porta l'íncipit $D e$ animalibus i es compon de tres parts: De historia animalium («Sobre la recerca entorn els animals»), de 10 llibres; De partibus animalium («Sobre les parts dels animals»), de 4 llibres, i De generatione animalium («Sobre la generació dels animals»), de 5 llibres ${ }^{9}$. La traducció de Michael Scot de 19 llibres va tenir una gran difusió entre els seus contemporanis ${ }^{10}$. La seva versió fou emprada per Vincent de Beauvais, Pere Hispà o Albert Magne, per esmentar alguns dels autors més representatius que van escriure comentaris dels llibres sobre els animals. També es va difondre a través d'antologies com la De animalibus auctoritates ${ }^{11}$ i en enciclopèdies com la De floribus rerum naturalium (c. 1230) d'Arnau de Saxònia ${ }^{12}$.

8. La traducció fou realitzada entre 1210 i 1217 i fou aquesta darrera data amb gran probabilitat I'any de finalització; Wingate, Sybil D. The medieval Latin versions of the Aristotelian scientific corpus, with special reference to the biological works. London: University of London; 1931, p. 74. Oppenraay, Aafke M. I. van. Michael Scot's Arabic-Latin translation of Aristotle's Books on Animals. Some remarks concerning the relation between the translation and its Arabic and Greek sources. In: Steel, Carlos; Guldentops, Guy; Beullens, Pieter, eds. Aristotle's animals in the Middle ages and Renaissance. Leuven: Leuven University Press; 1999, p. 31-43. Un temps després, cap el 1230, quan Michael Scot es trobava al servei de Frederic II a Sicília, va traduir de l'àrab al Ilatí els 19 llibres que conformen els Libri de animalibus d'Avicenna.

9. Editats en els volums 5. 2 i 5.3 de la col.lecció ASL «Sobre les parts dels animals» i «Sobre la generació dels animals». Edició a ASL 5.2 De animalibus. Michael Scot's Arabic-Latin translation, Volume 2 Books XI-XIV: Parts of Animals. Ed. Aafke M. I. van Oppenraay. Leiden: E.J. Brill; 1998; ASL 5.3 De animalibus. Michael Scot's Arabic-Latin translation, Volume 3 Books XV-XIX: Generation of Animals. With a Greek Index to De generatione animalium. Ed. H. J. Drossaart Lulofs. Leiden: E.J. Brill; 1992. El volum 5. 1 de la col.lecció de I'ASL que inclou l'edició dels textos que provenen de l'àrab De historia animalium encara no està disponible. Aquesta darrera obra és la més primerenca i extensa del conjunt de llibres i segueix l'estructura de 10 llibres que conté l'obra grega tal i com la va editar Andrònic de Rodes.

10. Wingate, n. 8, p. 72-85.

11. Extracte de Libro Aristotelis de naturis animalium. Vegeu Wingate, n. 8, p. 79; Buellens, Pieter. A 13th-century florilegium from Aristotle's books on animals: Auctoritates extracte de libro Aristotilis de naturis animalium. In: Steel, n. 8, 1999, p. 69-96.

12. Draelants, Isabelle. La transmission du «De animalibus» d'Aristote dans le «De floribus rerum naturalium» d'Arnoldus Saxo. In: Steel, n. 8, 1999, p. 126-158. 
Entre 1262 i 1263, William de Moerbeke va dur a terme una nova traducció dels llibres sobre els animals a partir de les versions que provenien del grec. Moerbeke va reunir en 21 llibres el De historia animalium ${ }^{13}$, el De progressu animalium, el De motu animalium ${ }^{14}$, el De partibus animalium ${ }^{15}$ i, finalment, el De generatione animalium ${ }^{16}$. Un element distintiu d'aquesta versió és la inclusió de dos breus tractats d'Aristòtil sobre la progressió i el moviment dels animals, el De motu animalium i el De progressu animalium, que no havien estat traduïts en la versió que procedia de l'àrab, de Michael Scot. Tanmateix, això no va impedir que el De motu animalium fos mencionat per Averrois, comentat per Pere d'Alvèrnia o parafrasejat per Albert el Gran a través d'altres traduccions ${ }^{17}$.

La primera vegada que aquests dos breus tractats van ser difosos en la versió llatina a Occident va ser a partir de la nova traducció de Guillem de Moerbeke. Una vegada traduïts al llatí, aquests tractats van circular en més

13. Els primers 5 llibres dels 10 que conformen el De historia animalium estan editats a AL XVII 2.I.1 De historia animalium. Translatio Guillelmi de Morbeka. Pars prima: lib. I-V. Beullens, Pieter; Bossier, Fernand, eds. Leiden - Boston - Köln: E. J. Brill; 2000. Els següents 5 llibres (llibres $\mathrm{VI-X)} \mathrm{estan} \mathrm{en} \mathrm{procés} \mathrm{d'edició} \mathrm{a} \mathrm{AL} \mathrm{XVII} \mathrm{2.} \mathrm{I.} \mathrm{2,} \mathrm{tot} \mathrm{i} \mathrm{que} \mathrm{el} \mathrm{text} \mathrm{es} \mathrm{pot} \mathrm{consultar} \mathrm{a} \mathrm{I'ALD.}$

14. Aquestes dues obres componen els llibres XI i XII d'aquesta collecció sobre els animals (segona i tercera part). L'edició crítica del text de William de Moerbeke a AL XVII 2. II-III Aristoteles. Guillelmus de Morbeka. De progressu animalium. De motu animalium. Translatio Guillelmi de Morbeka. De Leemans, Pieter ed. Turnhout: Brepols; 2011.

15. L'edició crítica de la versió llatina del De partibus animalium que prové del grec està en procés d'edició a AL XVII 2.I.2 De historia animalium. Translatio Guillelmi de Morbeka. Pars secunda: lib. VI-X i XVII 1-2.IV De partibus animalium. Translatio anonyma et Translatio Guillelmi de Morbeka. Aquest text, que també es pot consultar a I'ALD, conforma la quarta part de la traducció de Moerbeke dels llibres sobre els animals d'Aristòtil (Ilibres XIII-XVI). Sobre aquesta traducció vegeu Rossi, Pietro B. Note sulla tradizione della «Translatio Guillelmi» del «De partibus animalium». In: Beyers, Rita, ed. Tradition et traduction: les textes philosophiques et scientifiques grecs au Moyen Âge Latin: hommage à Fernand Bossier. Leuven: Leuven University Press; 1999, p. 167-197.

16. Aquesta és la cinquena i última part de la col-lecció sobre els animals de Moerbeke amb els Ilibres XVII-XXI. Edició del text a AL XVII 2.V De generatione animalium. Translatio Guillelmi de Moerbeka. Ed. H. J. Drossaart-Lulofs. Bruges - Paris: Desclée De Brouwer; 1966.

17. La versió llatina que coneixem fragmentàriament a través de la paràfrasi que Albert el Gran va fer en el seu De principiis motus processivi prové, segons indica l'anàlisi crítica, d'una traducció del grec diferent de la realitzada per Guillem de Moerbeke. Hom pot trobar l'edició reconstruïda d'aquest tractat a $A L$ XVII 1.III Aristoteles, De motu animalium. Fragmenta Translationis anonymae. De Leemans, Pieter, ed. Turnhout: Brepols; 2011; a part de l'estudi introductori de l'obra vegeu De Leemans, Pieter. The discovery and use of Aristotle's «De Motu Animalium» by Albert the Great. In: Aertsen, Jan A.; Speer, Andreas, eds. Geistesleben im 13. Jahrhundert. Berlin: De Gruyter; 2000, p. 170-188. 
d'una col-lecció. En la taxació dels exemplaria oficials d'Aristòtil de 1304 de París, trobem aquests dos tractats inclosos dins de dues col-leccions i això va donar lloc a la circulació de dos exemplars diferents que van derivar en un gran nombre de manuscrits. Aquesta situació va contribuir al fet que, per una banda, fossin considerats com una part del conjunt d'escrits dels animals [De historiis animalium] i, de l'altra, que fossin associats al conjunt de tractats que conformen el grup d'escrits conegut com Parva naturalia [Item de motibus animalium et aliorum parvorum ${ }^{18}$. En aquest conjunt de tractats, l'escrit sobre el moviment dels animals hi tenia una certa preponderància ${ }^{19}$. La majoria de tractats que conformen els Parva naturalia eren coneguts des del segle $\mathrm{X}$ en versions àrabs ${ }^{20}$. Les versions llatines d'aquest conjunt de tractats es van difondre a partir del segle XII a través de la traducció de Giacomo da Venezia, i el moment de gran difusió va ser durant el segle XIII' ${ }^{21}$.

La nova traducció de Moerbeke es va erigir com a traducció oficial de les obres d'Aristòtil impulsada per la Universitat de París i això va acabar per desplaçar les altres traduccions tot i la difusió que havien tingut. També hi ha rastre d'altres traduccions anònimes que provenen del grec. Aquest és l'exemple de la traducció anònima del De motu animalium, d'origen molt probablement italià i anterior a la de Moerbeke, que coneixem fragmentàriament per la paràfrasi que Albert el Gran en va fer en el seu De principiis motus processivi ${ }^{22}$. També hi hagué altres traduccions del $D e$ partibus animalium, que en el seu conjunt van donar un gran número de variants ${ }^{23}$.

18. De Leemans, n. 14, 2011, p. XLIII i seg. Vegeu també De Leemans, Pieter. Secundum viam naturae et doctrinae. Lire le De motu animalium et les Parva naturalia d'Aristote au Moyen Âge. In: Grellard, Christophe; Morel, Pierre-Marie, eds. Les Parva naturalia d'Aristote: fortune antique et médiévale. Paris: Publications de la Sorbonne; 2010, p. 197-220; Beullens, Pieter. Quelques observations sur la traduction del «Histoire des animaux» d'Aristote par Guillaume de Moerbeke. Bulletin de Philosophie Médiévale. 1992; 34: 181-196.

19. Sobre la recepció dels Parva naturalia als ambients universitaris vegeu Federici Vescovini, Graziella. La tradizione dei Parva Naturalia nell'insegnamento universitario medievale (secoli XIII e XIV). In: Crisciani, n. 5, 2004, p. 125-141.

20. Aquest conjunt de tractats foren traduits a l'àrab ja des de finals del segle X. Sobre aquesta qüestió vegeu Hansberger, Rotraud. Kitâb al-Hiss wa-l-mahsùs. Aristotle's Parva naturalia in Arabie Guise. In: Grellard, n. 18, p. 143-162.

21. Wingate, n. 8, p. 47-52; Brams, n. 2, p. 37-51.

22. Vegeu la nota 17.

23. Sobre aquesta versió vegeu Rossi, Pietro. La Translatio Anonyma e la Translatio Guillelmi del De Partibus Animalium (Analisi del libro I). In: Brams, Josef; Vanhamel, Willy, eds. Guillaume 
L'arribada dels llibres sobre els animals d'Aristòtil a la cultura occidental va comportar la difusió de noves teories a l'àmbit de la biologia i zoologia que establiren un nou paradigma en l'estudi de la naturalesa humana. Això va tenir la seva repercussió en disciplines com la filosofia natural i la medicina i va donar lloc a una important producció escrita. Albert el Gran desenvolupà el comentari De animalibus de 26 llibres per introduir-se en aquests dos camps d'estudi ${ }^{24}$. Durant els segles XII i XIII, els llibres sobre els animals foren assimilats progressivament al currículum mèdic; el metge italià Pietro d'Abano recomanava el De animalibus als seus estudiants ${ }^{25}$. Un dels primers comentaris d'aquests llibres en el camp de la medicina fou el de Pere Hispà, amb el Questiones super libro de animalibus, escrit entre 1246 i 1249 a Siena ${ }^{26}$. El seu treball posa de relleu la interacció i les desavinences entre la filosofia natural i la medicina, un àmbit en el qual els llibres sobre els animals també van aflorar en les obres d'Arnau de Vilanova i Bernard de Gordon ${ }^{27}$.

\section{Els llibres sobre els animals i la Facultat de Medicina de Montpeller durant la segona meitat del segle XIII}

Hi ha constància de l'aplicació dels llibres naturals en làmbit de la medicina de Montpeller des de mitjans del segle XIII. Tot i que els estatuts inicials de

de Moerbeke. Recueil d'études à l'occasion du 700e anniversaire de sa mort. Leuven: Leuven University Press; 1989, p. 193-220.

24. Albert el Gran va dur a terme el De animalibus basat en la traducció de Michael Scot, tot i que també hi ha traces de la traducció de Moerbeke que utilitzà a partir del moment que en va disposar. Vegeu al respecte Goldstein-Préaud, Tamara. Albert le Grand et les questions du XIIle siècle sur le «De animalibus» d'Aristote. History and philosophy of the life sciences; 1981; 3: 61-71; Sobre Albert el Gran i les qüestions entre medicina i filosofia natural vegeu De Asúa, Miguel. Peter of Spain, Albert the Great and the «Quaestiones de animalibus». Physis. Rivista internazionale di storia della scienza; 1997; 34: 1-30.

25. Siraisi, Nancy G. Arts and sciences at Padua: the Studium of Padua before 1350. Toronto: Pontifical Institute of Mediaeval Studies; 1973, p. 127-128

26. Vegeu al respecte Navarro Sánchez, Francisca. Petri Hispani, Questiones super libro «De animalibus» Aristotelis: estudio, edición y traducción del ms. 1877 de la B.N. de Madrid. Bellaterra: Universitat Autònoma de Barcelona; 2009 [Consultable a: http://hdl.handle. net/10803/5558 (consultada el 22 de maig de 2013)]; De Asúa, Miguel. El comentario de Pedro Hispano sobre el De animalibus. Transcripción de las Quaestiones sobre la controversia entre médicos y filósofos. Patristica et Mediaevalia; 1995; 16: 45-66.

27. De Asúa, Miguel. Medicine and philosophy in Peter of Spain's commentary on De animalibus, In: Steel, n. 8, p. 189-211. 
la Universitat de Montpeller de 1220 no especifiquen quin era el currículum mèdic, com tampoc ho fan les posteriors reformes dels estatuts dels anys 1239 i 1240, les obres i els comentaris que han perdurat de la segona meitat del segle XIII indiquen que el currículum mèdic girava al voltant de l'Articella ${ }^{28}$. El primer currículum detallat el coneixem a través de la butlla Ad pascendum oves de setembre de 1309, promulgada pel papa Clement V, en la qual Arnau hi va col-laborar establint la base del currículum mèdic amb el que Luis García Ballester va denominar el «nou Galè» ${ }^{29}$. Aquí no hi trobem referències directes a l'estudi d'aquests llibres tot i que durant aquesta època els metges ja els feien servir en les obres mèdiques. No és fins el 1340 que els estatuts fan referència directa als llibres sobre els animals quan els mestres prohibien llegir o ensenyar qualsevol llibre de gramàtica, lògica o ciència natural amb l'excepció del De animalibus ${ }^{30}$.

A Montpeller, un dels primers testimonis que evidencien l'ús dels llibres naturals d'Aristòtil utilitzats en comentaris al currículum mèdic és Magister Cardinalis, un mestre de medicina mencionat en els estatuts de 1240, just l'època en la que Henry de Winchester era Canceller de la universitat ${ }^{31}$. Si per una banda les dades sobre la seva vida són molt escasses, per l'altra es conserva un gran nombre de manuscrits que porten el seu nom, la major part dels quals són comentaris a l'Articella, que enriqueixen la producció mèdica d'una figura que ha estat estudiada només parcialment ${ }^{32}$. El manuscrit

28. Germain, Alexandre, ed. Cartulaire de l'Université de Montpellier. Vol. 1 (1181-1400). Montpellier: Imprimé par la maison Ricard Frères; 1890, doc. 4, p. 185-186 i doc. 5, p. 186-190.

29. Germain, n. 28, doc. 25, p. 219-221. Sobre aquesta qüestió vegeu García Ballester, Luis. Arnau de Vilanova (c. 1240-1311) y la reforma de los estudios médicos de Montpeller (1309): El Hipócrates latino y la introducción del nuevo Galeno. Dynamis. 1982; 2: 97-158 [traducció anglesa i actualitzada: The new Galen: a challenge to Latin Galenism in thirteenth-century Montpellier. In: Fischer, Klaus-Dietrich; Nickel, Diethard; Potter, Paul, eds. Text and tradition. studies in Ancient Medicine and its transmission. Presented to Jutta Kollesch. Studies in Ancient Medicine. Leiden: Brill; 1998, p. 55-83].

30. Germain, n. 28, doc. 68, art. XXXI, p. 350.

31. En el document de complementació dels estatuts de la Universitat de medicina de Montpeller del 14 i 21 de gener de 1240, apareix Magister Cardinalis com a professor; Germain, n. 28, doc. 5, p. 186. Aquest nom no torna a aparèixer en els següents documents.

32. Magister Cardinalis té, en efecte, una important producció inèdita que encara no ha estat analitzada en el seu conjunt. Per a la llista de manuscrits vegeu Thorndike, Lynn; Kibre, Pearl. A Catalogue of incipits of medieval scientific writings in Latin (2nd ed.). London: Mediaeval Academy of America; 1963, col. 1771; Wickersheimer, Ernest. Dictionnaire Biographique des médecins en France au Moyen Âge. Genève: Droz; 1979, p. 94-95; Jacquart, Danielle. Ernest Wickersheimer. Dictionnaire biographique des médecins en France au Moyen Âge. Nouvelle 
conservat a la Bibliothek des St. Nikolaus-Hospitals de Bernkastel-Kues ofereix una visió global sobre el seu treball amb comentaris a la Isagoge, al Tegni de Galè, o als aforismes d'Hipòcrates ${ }^{33}$, tot i que la seva producció va més enllà dels comentaris al currículum mèdic, amb obres sobre el tractament de la visió ${ }^{34}$, la lepra ${ }^{35}$ o receptes per a la quartana ${ }^{36}$, per esmentar alguns dels tractats que porten el seu nom.

Michael McVaugh ha posat l'atenció sobre aquesta figura en destacar que fou el primer metge que va introduir els treballs de Galè i l'Articella en el currículum de la Facultat de medicina de Montpeller ${ }^{37}$. En el seu comentari a la Isagoge s'inclouen més d'una vintena de referències no només a les obres de lògica d'Aristòtil sinó també dels seus llibres naturals, entre els quals es troben el De animalibus. L'ampli ventall d'obres que utilitza en aquest comentari invita a pensar en una assimilació del corpus aristotèlic, ja present en l'àmbit mèdic de Montpeller de mitjans del segle XIII. Cardinalis menciona com a mínim en dues ocasions el De animalibus d'Aristòtil, concretament el tractat De generatione animalium ${ }^{38}$. Aquestes referències

éd. sous la direction de Guy Beaujouan. Supplément. Genève - Droz: Champion; 1979, p. 53-54.

33. Bernkastel-Kues, Bibliothek des St. Nikolaus-Hospitals, Ms. 222, fols. 1 r-181r.

34. Jacquart, n. 32, p. 53-54; Wickersheimer, n. 32, p. 95.

35. Thorndike, n. 32, col. 361; Wickersheimer, n. 32, p. 95.

36. Jacquart, n. 32, p. 53.

37. McVaugh, Michael R. The humidum radicale in the 13th Century Medicine. Traditio. 1974; 30: 271; Sobre aquesta qüestió vegeu també García Ballester, n. 29, p. 101-102; Salmón, Fernando. La obra médica de Arnau de Vilanova en Montpellier. In: Granier, Thomas; Le Blévec, Daniel, eds. L'Université de médecine de Montpellier et son rayonnement (XIIle-XVe siècles). Actes du colloque international de Montpellier organisé par le Centre historique de recherches et d'études médiévales sur la Méditerranée occidentale (Université Paul Valéry - Montpellier III), 17-19 mai 2001. Turnhout: Brepols; 2004, p. 134-137; Crisciani, Chiara; Ferrari, Giovanna. Introduzione. In: Arnau de Vilanova. Tractatus de humido radicali, edició crítica de Michael McVaugh i estudi introductori de Chiara Crisciani i Giovanna Ferrari. Barcelona: Universitat de Barcelona - Fundació Noguera; 2010, p. 399; Lugt, Maaike van der. Neither ill nor healthy. The intermediate state between health and disease in medieval medicine. Quaderni Storici. 2011; 136: 21-23.

38. Glosa Cardinalis super lohannicium, n. 33, fols. 11 ra i 14ra: «ltem dicit Aris. in libro de animalibus quod in corpore est tantum unum membrum principale (11 ra)» i «item dicit Ar. in libro de animalibus quod non est differentia inter sermonem dicens quod oculus videt et quod extravertitur spiritus»(14ra). El meu agraïment al professor Michael McVaugh per les referències. De les citacions de Cardinalis podem constatar que la primera referència remet al De generatione animalium, IV, 4, 772b27-773a (trad. de Michael Scot, ASL 5. 3 De animalibus, n. 9, p. 194): «unum membrum principale»; la segona referència fa menció al De generatione animalium, V, 1-2, 780 b15 (trad. de Michael Scot ASL 5. 3 De animalibus, n. 9, p. 221): «dicentis 
foren emprades també per altres metges com Pere Hispà ${ }^{39}$. Dit això, és probable que el mateix Cardinalis hagués estat un dels mestres d'Arnau de Vilanova quan va estudiar medicina durant la dècada de 1260 o, com a mínim, podem suposar que els seus comentaris a l'Articella foren coneguts durant la seva etapa com a estudiant.

No obstant, Cardinalis no és l'únic testimoni d'aquesta època en utilitzar els llibres sobre els animals a Montpeller. També ho fa, per exemple, Gilbert d'Anglaterra (anglicus), un metge format a París que arribà a Montpeller als volts de 1240, també amb una important producció escrita ${ }^{40}$. En el seu comentari al líquid de la orina d'Egidio, el Commentarii in versus Aegidii de urinis, Gilbert proporciona una dotzena de referències a Aristòtil, entre les quals es troba també el De animalibus ${ }^{41}$. En una altra obra de molta més difusió, el Compendium medicinae, Gilbert proporciona un gran nombre de citacions a diverses obres d'Aristòtil, entre les que destaquen, principalment, els Meteora $^{42}$. Entre aquestes citacions també hi diverses referències als llibres sobre els animals d'Aristòtil. En aquest domini es pot constatar una certa influència d'autors àrabs ja que Gilbert extreu diverses referències d'Aristòtil a través de l'obra d'Avicenna ${ }^{43}$. Això posa de relleu el paper que alguns autors van tenir a l'hora de difondre aquestes referències i com

quod oculus videt et inter sermonem dicentis quod visus exit ad visum». Les dues cites ens remeten a la traducció de Michael Scot, la traducció llatina disponible durant aquests anys, i a més, aquests conceptes als quals fa referència Cardinalis no apareixen en la traducció de Moerbeke.

39. Cal tenir present que Pere Hispà fa servir la mateixa referència per l'explicació de la quaestio 16 del seu comentari De animalibus: «Dicendum quod philosophus ponit unum membrum principale quia corpus hominis componitur»; vegeu De Asúa, n. 27, p. 204, nota a peu de pàg. 64 i p. 201, nota a peu de pàg. 56. En canvi aquestes referències no hi són presents en I'obra de Henry de Winchester. Sobre aquest assumpte vegeu McVaugh, n. 37, p. 259-283; Crisciani, n. 37, p. 319-567.

40. McVaugh, Michael R. Who was Gilbert the Englishman? In: Brown, George Hardin; Voigts, Linda E. eds. The study of medieval manuscripts of England. Turnhout: Brepols Publishers; 2010, p. 295-324.

41. McVaugh, Michael R. Medicine and arts in the thirteenth-century Paris. In: Spencer E. Young ed. Crossing boundaries at medieval universities. Leiden - Boston: Brill; 2011, p. 189-211. Una relació dels manuscrits d'aquest tractat a Riha, Ortrun. Gilbertus Anglicus und sein «Compendium medicinae»: Arbeitstechnik und Wissensorganisation. Sudhoffs Archiv. 1994; 78 (1): 64-65.

42. Per una anàlisi de les autoritats emprades en el tractat vegeu Kurdziałek, Marian. Gilbertus Anglicus und die psychologischen Erörterungen in seinem Compendium Medicinae. Sudhoffs Archiv. 1963; 47 (2): 106-126, especialment per Aristòtil, 109-117.

43. Kurdziałek, n. 42, p. 110. 
alguns metges les van conèixer no a través del text original sinó de tercers. En qualsevol cas, aquests exemples posen de relleu que a mitjans del segle XIII, els llibres sobre els animals estaven presents en les obres mèdiques de Montpeller i en les discussions entre medicina i filosofia natural ${ }^{44}$.

Arnau de Vilanova va escriure un dels seus primers tractats al voltant de 1270 i en aquesta obra va fer referència per primera vegada a una idea que apareix al breu tractat sobre el moviment dels animals d'Aristòtil. Però fou a partir 1290, quan Arnau tornà a Montpeller per exercir la docència, que va elaborar una important producció mèdica i, en aquest context, va emprar un ampli ventall de les obres aristotèliques amb diverses referències als llibres sobre els animals d'Aristòtil.

\section{El cor i el moviment dels animals}

Un dels exemples més primerencs és el Tractatus de amore heroico, un opuscle d'Arnau de Vilanova elaborat al voltant de 1270 i dedicat a la malaltia de l'amor heroic, en el qual Arnau remet en una oració al $D e$ motu animalium $^{45}$. En aquest breu opuscle, Arnau aplega el saber mèdic de l'època sobre la malaltia de l'amor heroic, el trastorn que causava la malaltia de l'amor obsessiu. En el segon capítol, Arnau explica quina és la causa subjacent d'aquesta alteració, que no és sinó un judici erroni de la virtut estimativa ${ }^{46}$. La causa que provoca aquesta fallida cal cercar-la, doncs, en l'òrgan que duu a terme les seves accions, és a dir, el cervell. En aquest context, Arnau fa referència a l'obra aristotèlica De motu animalium per justificar que

44. Arnau menciona l'obra de Gilbert en el seu tractat De consideracionibus operis medicine sive de flebotomia; Arnau de Vilanova. Tractatus de consideracionibus operis medicine sive de flebotomia. Edició crítica per Luke Demaitre, estudi per Pedro Gil-Sotres i Luke Demaitre. AVOMO IV. Barcelona: Universitat de Barcelona; 1988, p. 60 i 113: «et summis que potissime magni voluminis sunt, sicut in historiis Gilleberti».

45. Arnau de Vilanova. De amore heroico. De dosi tyriacalium medicinarum. Edició crítica i estudi per M. R. McVaugh. AVOMO III. Barcelona: Universitat de Barcelona; 1985; text reproduït amb la traducció al català a Arnau de Vilanova. Tractat sobre l'amor heroic. A cura de Michael McVaugh [introducció i text Ilatí] i Sebastià Giralt [traducció catalana i notes] (Col.lecció Barcino, 7) Barcelona: Barcino; 2011.

46. Arnau de Vilanova. De amore heroico, n. 45, p. 48, lin. 2: «erroneo iudicio causatur estimative virtutis». 
«quan un objecte agradable o plaent es presenta a l'ànima, el goig del plaer aprehès fa que els esperits es multipliquin al cor i s'esclafin de sobte. Després d'aquest escalfament sobtat - segons les recerques fetes sobre els moviments dels animals per aquella branca del saber que tracta del moviment del corsón tramesos a tots els membres del $\cos »^{47}$.

Arnau fa referència a la idea d'Aristòtil que el cor és el centre de la sensació i el principi del moviment dels animals ${ }^{48}$. El moviment sorgeix, doncs, quan per calor, fred o qualsevol altre afecció es produeix una alteració en la regió del cor, animada pel pensament o la percepció dels sentits, i que provoca una reacció al $\cos ^{49}$. Gairebé trenta anys després de l'elaboració del tractat sobre l'amor heroic, Arnau va tornar a fer servir la mateixa referència d'Aristòtil en el Tractatus de consideracionibus operis medicine sive de flebotomia, escrit entre 1298 i $1300^{50}$. En aquest cas, Arnau va utilitzar l'argument d'Aristòtil que havia utilitzat anys abans però sense esmentar el paper del cor sinó remetent a la consideració que és la forma representada en la imaginació d'una persona la que mou el seu cos.

Quan Arnau va utilitzar per primera vegada el De motu animalium va ser molt poc després que fos traduït al llatí per Guillem of Moerbeke. La versió més estesa era, doncs, la de Moerbeke i la més factible de ser consultada, atès que fou en el context de la Universitat de Montpeller on Arnau va desenvolupar aquest opuscle. Arnau podia haver conegut el tractat a través d'algun dels nombrosos manuscrits que derivaven de les dues col-leccions que van esdevenir oficials a París. De fet, la còpia manuscrita de l'obra De motu animalium que es conserva a la Facultat de Medicina de Montpeller és una versió altament contaminada, extreta de diversos manuscrits independents i de la versió parisenca ${ }^{51}$. Així doncs, l'exemplar procedeix de la traducció

47. Arnau de Vilanova. De amore heroico, n. 45, p. 49, lin. 22-25: «Cum enim anime gratum seu delectabile presentatur, ex gaudio delectabilis apprehensi spiritus in corde multiplicati subito calefiunt, et calefacti subito — prout inde motibus animalium inquisitum est ea parte qua de motu cordis agitur - delegantur ad membra corporis universa». Traducció a càrrec de Sebastià Giralt a Arnau de Vilanova. Tractat sobre I'amor heroic, n. 45, p. 69.

48. Aristòtil, De motu animalium, 700b5-703a28.

49. Aristòtil, De motu animalium, 702a.

50. Arnau de Vilanova, Tractatus de consideracionibus operis medicine, n. 44, p. 196, lin. 23-24 i p. 197, lin. 1-2: «Hoc autem in parte naturalis philosophie verificatur, scilicet in consideracione de motibus animalium ubi ostenditur quod forma representata in ymaginacione movet corpus sibi coniunctum et ea que in eo sunt».

51. Vegeu al respecte De Leemans, n. 14, p. 35 i 51. 
de Moerbeke i no de l'anònima, que ens ha arribat només a través de la paràfrasi d'Albert el Gran i que, si fem cas de les seves paraules, aquesta traducció procediria de la Campània, al sud d'Itàlia i relativament a prop de Grècia ${ }^{52}$. Tanmateix, en aquest cas també hi ha altres possibles vies de coneixement ja que la idea de la importància del cor en el moviment que utilitza Arnau és una afirmació que estava inclosa en florilegis i era prou coneguda pels estudiants d'arts la qual cosa, en la gran majoria de casos, havien cursat abans d'estudiar medicina ${ }^{53}$.

\section{El cor com a principi de generació}

Una altra afirmació del cor que prové d'escrits d'Aristòtil sobre els animals és la que trobem en el Tractatus de intentione medicorum, un opuscle mèdic que Arnau de Vilanova va escriure cap el 1290 per resoldre el problema de les contradiccions entre les autoritats, representades per Aristòtil i Galè. Era aquesta una preocupació dels metges de l'època que, més enllà de la personificació, posa en evidencia la confrontació i desavinences entre filosofia natural i medicina ${ }^{54}$. El Tractatus de intentione medicorum fou elaborat durant la seva etapa com a docent a la Facultat de medicina de Montpeller amb l'objectiu de definir els límits de la certesa mèdica i l'ús que el metge ha de fer de la ciència natural. Per fer-ho, Arnau presenta una selecció de discussions de l'època entre medicina i filosofia natural per tal de conjugar la filosofia aristotèlica amb la medicina galènica. En una de les discussions centrada en la controvèrsia sobre el cor com a únic òrgan principal, Arnau remet al De partibus animalium.

Arnau presenta la posició contradictòria a primera instància entre Aristòtil i Galè; Aristòtil afirma que el cor és el membre principal del cos mentre que Galè sosté que és un membre més dels quatre que considera

\footnotetext{
52. Així ho expressa Albert el Gran: «in Campania iuxta Greciam».

53. L'afirmació del cor la trobem també en el florilegi d'Autoritats a Hamesse, Jacqueline. Les Auctoritates Aristotelis. Un florilège médiéval. Étude historique et édition critique. Louvain: Publications universitaires. Paris: Bétrice-Nauwelaerts; 1974, p. 208, núm. 8: «Principium motus in animalii est in corde».

54. Arnau de Vilanova. Tractatus de intentione medicorum. Edició crítica i estudi per M. R. McVaugh. AVOMO V.1. Barcelona: Universitat de Barcelona - Fundació Noguera; 2000.
} 
com a principals ${ }^{55}$. En aquest cas, Arnau utilitza l'afirmació d'Aristòtil del capítol quart del llibre tercer del De partibus animalium, en el qual parla del cor com el primer receptacle que es forma i el lloc on s'originen tots els moviments causats per les sensacions ${ }^{56}$. Aquesta discussió sobre la primacia del cor entre les dues autoritats fou abordada per diversos metges i filòsofs abans d'Arnau - com per exemple la quaestio 16 del comentari De animalibus de Pere Hispà-, però el recurs que utilitza Arnau per arribar a un punt en comú és afirmar que el cor és el principi primer i original, on la virtut vital del cos és més evident, una idea que Galè no nega ${ }^{57}$. Aquí constatem allò que Michael McVaugh ha definit com l'instrumentalisme mèdic, mitjançant el qual, Arnau argumenta que el cor és el primer principi, les forces del qual dirigeixen tots els altres i, per tant, els altres tres òrgans esdevenen instruments del $\operatorname{cor}^{58}$. Així, doncs, el metge només anomena els membres principia en la mesura que pugui demostrar-hi l'activitat de la força directriu del cor, i, per aquesta raó, l'esquema que sosté Galè amb el cor, el cervell, el fetge, i els testicles - en cada un dels quals resideix la virtut natural- no ha de repugnar a Aristòtil ${ }^{59}$.

\section{La generació dels animals: humitat radical i humitat espermàtica}

L'obra que porta el nom de Tractatus de humido radicali és un altre dels escrits on apareixen diverses referències a Aristòtil. Aquesta és una obra de filosofia natural que tracta sobre la naturalesa de l'humit radical, això

55. Arnau de Vilanova. Tractatus de intentione medicorum, n. 54, p. 103, lin. 9-12: «Docet enim medicus ibidem principia seu fundamenta membrorum esse quator, visus in hoc obviare directe naturali philosopho inter omnia membra tantum unum esse ponenti principium seu fundamentum ceterorum membrorum».

56. Aristòtil, De partibus animalium, III. 4, 666a10-b1.

57. Arnau de Vilanova. Tractatus de intentione medicorum, n. 54, p. 106, lin. 15-16: «Quod enim philosophus dicit membrum unum esse principium inter membra, loquitur de principio primo et originali, et hoc medicus non negat».

58. McVaugh, Michael R. Introduction. In: Arnau de Vilanova. Tractatus de intentione, n. 54, p. 30-40 i 145-155.

59. Arnau de Vilanova. Tractatus de intentione medicorum, n. 54, p. 106, lin. 20-26: «Quod autem medicus dicit quatuor esse principia, loquitur de principiis proximis et manifestativis, et hoc non negat philosophus; immo potius asserit quod licet omnes virtutes a corde oriantur, non tamen omnes in corde manifestantur suis actionibus sed potius in aliis membris que cordi instrumentaliter famulantur - utpote animalis in cerebro, nutritiva in epate, generativa in testiculis». 
és un fluid elemental que resta dispers per l'organisme i que està en relació directa amb la vida i la nutrició ${ }^{60}$. D’aquí en sorgeix la idea d'una proporció entre la calor i la humitat lligada amb la durabilitat de la vida i s'estableix una marcada distinció entre la humitat radical i la humitat espermàtica. En aquest sentit, Aristòtil té una important aportació en la definició de l'humit radical en obres com la Metafísica, el De generatione, la col-lecció dels Parva naturalia i els llibres sobre els animals.

En aquest cas, Arnau utilitza l'expressió «Aristoteles XV de animalibus docet» i aporta l'afirmació que apareix al De generatione animalium segons la qual l'esperma és, o conté en si mateixa, el principi de generació ${ }^{61}$. Cal tenir present que Arnau remet a la distribució de llibres feta per Michael Scot. Aixó no vol dir que consultés directament la seva traducció ja que aquest tòpic fou abordat per altres metges abans que ho fes Arnau, com per exemple Gilbert d'Anglaterra. A continuació, Arnau fa referència a l'afirmació d'Aristòtil que examina la raó de la formació dels testicles quan afirma que la naturalesa ho crea tot o bé perquè és necessari o bé perquè és millor ${ }^{62}$. Arnau fa referència a la qüestió tractada per Aristòtil sobre l'equivalència del líquid seminal de les dones amb el dels homes i el seu

60. Sobre aquesta qüestió vegeu la nota 37.

61. Arnau de Vilanova. Tractatus de humido radicali, n. 37, p. 303, col. 668 i seg.: «Ex quo habetur id quod Aristoteles XV de animalibus docet, scilicet quod a residuo alimenti uniuscuisque membri, licet maxime principalium, potest sperma quod est principium generationis descindi; et supra dictam rationem fundat se ibi». Referència a Aristòtil. De generatione animalium, I.18, 724b22-30 (trad. de William de Moerbeke, AL XVII 2.V De generatione animalium, n. 16): «Sperma ergo dicitur illud quod exit ex generanti ex omnibus modis animalium coeuntium, et est naturaliter primum in quo est principium generationis». En aquest cas, la traducció Ilatina de Michael Scot utilitza el mateix vocabulari, ASL 5. 3 De animalibus, n. 9, p. 34.

62. Arnau de Vilanova, Tractatus de humido radicali, n. 37, p. 303, col. 679- 685: «Non ergo a testiculis habet hoc, et hoc etiam affirmat demonstratio Aristotelis XV, ubi ostendit testiculorum facturam non esse necessariam nisi ad salvationem individui in se, nec etiam in alio si non / ad salvationem speciei, sed solum factis sunt testiculi in hiis in quibus inveniuntur propter utilitatem ibidem ostensam». Referència a Aristòtil, De generatione animalium, I. 4, 717a15ss (trad. de William de Moerbeke, AL XVII 2.V De generatione animalium, n. 16): «Et si quis voluerit considerare in differentiis instrumentorum spermatis necessarium erit ei prius considerare in causis propter quas est substantia testiculorum. Si ergo natura facit omne quod facit aut propter id quod est necessarium ad faciendum aut propter id quod est melius, debemus scire quod hoc membrum etiam est factum propter alterum istorum. Et manifestum est quod testiculis non indigetur necessario; quoniam si esset ita, essent testiculi in omnibus animalibus generatibus [...] et debemus ergo dicere quod creatio testiculorum est propter melius». En aquest cas, el vocabulari de la traducció llatina de Michael Scot també és molt similar, ASL 5. 3 De animalibus, n. 9, p. 7-8. 
paper en la procreació. Aristòtil ja va argumentar el rol passiu de la dona en aquest domini establint que no posseeix esperma i que la sang menstrual només aporta la matèria per a la procreació. Avicenna ja es va oposar a això en el Liber de animalibus i va argüir que les dones produïen una esperma que, tot i no posseir un poder generatiu igual que el dels homes, la seva influència es manifesta en la matèria de manera que determina el grau d'estructuració per part de l'home ${ }^{63}$. Arnau també fa referència a la discussió d’Aristòtil sobre el rol de l'esperma masculí i femení i la seva contribució en la matèria. En aquest sentit, Arnau assenyala que determinats filòsofs semblen afirmar que només l'esperma sigui materialment el principi del cos animat i l'esperma, que té materialment la raó del factor, penetra la constitució del cos animat ${ }^{64}$. Així, doncs, Arnau no entra més en aquesta qüestió argüint que és suficientment òbvia per a Aristòtil, així com també per a molts altres investigadors de les coses naturals que l'han comentat.

63. Avicenna. De animalibus. Venice: Joannes and Gregorius de Gregoriis, de Forlivio, ca. 1500, fols. 49r-49v.

64. Arnau de Vilanova. Tractatus de humido radicali, n. 37, p. 290, col. 193-197: «Preterea illi qui talia inveniunt videntur asserere quod solum sperma sit principium animati corporis materialiter, et quod sperma quod habet rationem factoris materialiter ingrediatur animati corporis constitutionem — quorum somnietatibus, quia iam Aristoteles obviavit sufficienter signis et rationibus et multi etiam expositores eius naturalium scrutatores, ideo ad presens pretermittimus illud». Referència a Aristòtil. De generatione animalium, 1. 21-22, 729a29 (trad. de William de Moerbeke, AL XVII 2.V De generatione animalium, n. 16): «Quod quidem igitur femella ad generationem genituram quidem non confert, confert autem aliquid, et hoc est menstruorum constitutio et proportionale in exsanguibus, ex dictis palam et secundum rationem universaliter intuentibus. Necesse enim esse aliquid generans et ex quo, et hoc si unum sit, specie differre et esse rationem ipsorum alteram, in separatas autem habentibus virtutes et corpora et naturam alteram esse facientis et patientis. Si igitur masculus est ut movens et faciens, femella autem, secundum quod femella, ut passivum, ad masculi semen femella conferet non genituram sed materiam».

En aquest cas, la traducció llatina de Michael Scot conté algunes variants, Aristòtil. De generatione animalium, I. 21-22, 729a29 (trad. de Michael Scot, ASL 5. 3 De animalibus, n. 9, p. 49): «Et manifestum est ex rationibus quas diximus quod femina non convenit generatione propter sperma quod exit ex ea, sed propter sanguinem menstruum et quod convenit ei in animalibus habentibus sanguinem. Et qui consideravit hoc consideratione universali inveniet nostrum sermonem verum; quoniam necessario debet esse generans et ex quo erit generatum, et non erit diversum quando genus fuerit idem, et diversas non est nisi ex parte distinctionis et formae. In rebus vero habentibus virtutes distinctas et corpora distincta et naturas diversas necessario diversatur virtus operantis et patientis. Si autem vir est sicut movens et operans et femina sicut patiens, manifestum est quod sperma feminae non convenit spermati viri in generatione, sed convenit sicut material». 
Arnau, emperò, no va ser l'únic metge de Montpeller que va utilitzar els llibres sobre els animals d'Aristòtil per tractar aquestes qüestions. Bernard de Gordon, professor de medicina a la mateixa Facultat, també va utilitzar un gran ventall d'obres d'Aristòtil en els seus llibres mèdics ${ }^{65}$. En el Tractatus de marasmode secundum intencionem Galieni, un text que versa sobre el marasme de Galè i l'humit radical, Bernard menciona el Liber de animalibus d'Avicenna i els llibres sobre els animals d'Aristòtil, concretament el De historia animalium i en dues ocasions el De generatione animalium, les dues obres emprades també per Arnau ${ }^{66}$.

Els dos metges es coneixien i malgrat les escasses mencions que es van fer l'un a l'altre en els seus escrits, els dos coneixien els seus respectius tractats i tenien en possessió algunes obres de cadascú ${ }^{67}$. Sembla que el Tractatus de marasmode de Bernard fou escrit no abans de 1305, és a dir, després del Tractatus de humido radicali ${ }^{68}$. En aquest cas, Bernard de Gordon discuteix sobre la segregació de l'esperma per part del mascle i la femella i recopila els arguments de les tesis aristotèliques en els quals el semen juga un rol formal en la concepció ${ }^{69}$. D’aquesta manera, estableix la distinció entre la forma i el principi de la matèria. Bernard sintetitza la posició d'Aristòtil envers aquesta qüestió i refuta novament l'opinió d'Aristòtil sobre que les dones no contribueixen a la veritable esperma, i afirma que és necessària la contribució de totes dues espermes per a la concepció ${ }^{70}$. Bernard utilitza

65. Demaitre, Luke. Doctor Bernard de Gordon, professor and practitioner. Toronto: Pontifical Institute of Mediaeval Studies; 1980, p. 24

66. Edició del Tractatus de marasmode de Bernard de Gordon a Demaitre, Luke. The medical notion of «withering» from Galen to the Fourteenth Century: The Treatise on Marasmus. Traditio. 1992; 47: 259-307.

67. McVaugh, Michael R. Nota sobre las relaciones entre dos maestros de Montpellier: Arnau de Vilanova y Bernardo Gordon. Asclepio. 1973; 25: 331-336.

68. Sobre aquesta qüestió vegeu Crisciani, n. 37, p. 400-403.

69. Bernard de Gordon. Tractatus de marasmode, n. 66, lin. 130: «Testiculi autem sunt in mulieribus propter necessitatem quoniam aliquo modo, licet debili, digeritur sanguis in testiculis mulierum: sicut / bene vult hoc Aristoteles XVo de animalibus, unde dicit quod non est digestum sicut semen viri, sed parum distat secundum ipsum a sanguine menstruo».

70. Bernard de Gordon. Tractatus de marasmode, n. 66, lin. 19-34 / lin. 19-29: «Respondeo et dico quod si nos velimus tenire viam phylosophorum dicemus quod non, quoniam semen viri tenet locum factoris et informantis sicut dicit Aristoteles $X V^{\circ}$ de hystoriis animalium; de semine autem mulieris dicit quod modicum distat a sanguine menstruo, et ideo non videtur habere operacionem; hoc idem vult Avicenna XV libri sui de historiis animalium. Et dicit Aristoteles quod conceptus potest fieri sine semine mulieris. Deinde venit Averroys $2^{\circ}$ sue theorice ubi dicit quod postquam audivit istud verbum ab Aristotele interrogavit multas mulieres que dicebant quod frequenter conceperant sine emissione seminis proprii». 
el De historia animalium d'Aristòtil en el mateix context que Arnau per debatre sobre la segregació de l'esperma masculina i femenina i el paper d'aquesta en la reproducció ${ }^{71}$.

Aquesta mateixa qüestió era objecte d'importants discussions entre els metges. El mateix Gilbert d'Anglaterra ja l'havia abordada uns anys abans. En aquest cas, Gilbert afirma, en paraules d'Avicenna, que així com la llet i el quall són part del formatge, així també les dues espermes són part de la substància de l'embrió ${ }^{72}$. A continuació contraposa aquesta afirmació amb la que presenta Aristòtil en el llibre quinzè del De generatione animalium on estipula que aquesta humitat no és espermàtica ${ }^{73}$. Aquesta és, doncs, la mateixa qüestió que analitzen Arnau i Bernard. De fet, aquesta discussió s'havia convertit en un tòpic en els debats mèdics, i per aquesta raó, les referències que utilitzen Arnau i Bernard en relació a Aristòtil, també poden provenir de l'estudi de les obres mèdiques que discuteixen sobre aquest assumpte i que remeten a les afirmacions pertinents, en aquest cas, al llibre quinzè dels animals de Michael Scot.

En el Tractatus de humido radicali, Arnau de Vilanova també fa referència al De historia animalium. En aquest cas, Arnau ens remet al procés d'embaràs descrit per Aristòtil per posar èmfasi en la creació de la forma quan afirma que en els embrions de sexe masculí el moviment es denota més cap a la dreta al voltant dels $40 \operatorname{dies}^{74}$. És en aquest moment

71. Aristòtil, De generatione animalium, 729a-b.

72. Gilberti Anglici. Compendium medicine Gilberti Anglici tam morborum universalium quam particularium nondum medicis sed chirurgicis utilissimum. Lugduni: Mercuriali; 1510, f. 289rb: «ltem dicit Auicena: «sperma mulieris est fundamentum particularis corporis infantis» [Canon, III, 20, 1, 3]. Item «sicut lac et coagulum est pars casei, ita duo spermata substantie embrionis [Canon, I, 1, 5, 1]». Item «contrarium dicit Aristoteles, XV, De naturis animalium: Exit quiddam a muliere, sed non spermaticum [Aristòtil, De generatione animalium, 728a]». Ad idem «dicit Remigius, quod a muliere procedit magis desudatio quam semen».

73. La referència ens remet al llenguatge de la traducció de Michael Scot. Aristòtil, De generatione animalium, I. 20, 728a (trad. de Michael Scot, ASL 5. 3 De animalibus, n. 9, p. 45): «Quod vero putant quidam homines quod femina conveniat generationi propter sperma quod eicit apud coitum propter delectationem est falsum, sed verum est quod exit quoddam humidum; sed non est spermaticum, immo est appropriatum loco, scilicet matrici, et accedit quibusdam mulieribus et quibusdam non».

74. Arnau de Vilanova, Tractatus de humido radicali, n. 37, p. 298, cols. 495-503: «Visum enim est, et iam Aristotelis recitavit, quod in aborsu masculorum embrionum humani corporis facto in $\mathrm{XL}$ die a conceptu vel circiter apparet creatura formata ad quantitatem unius magne formice, secundum distinctionem omnium membrorum exteriorum, tantum etiam addens quod veretrum et oculi ad comparationem stature totius sint valde magna, in quo corpore oportet 
quan l'embrió comença a definir-se i quan té els membres exteriors, el membre viril i els ulls desproporcionadament grans. La descripció d'Arnau és, en aquest cas, molt similar a la d'Aristòtil, tot i que no fa referència al moviment ni tampoc en remarca que quan es tracta d'un embrió femení, el moviment es denota al voltant dels 90 dies a l'esquerra ${ }^{75}$.

\section{Conclusions}

A través d'aquests exemples podem constatar que Arnau coneix gran part del corpus que configura els llibres sobre els animals d'Aristòtil. De tot el conjunt d'obres, Arnau utilitza referències que apareixen en el De motu animalium, el De partibus animalium, el De generatione animalium i el De historia animalium. Tanmateix, amb les citacions que proporciona Arnau es fa difícil esclarir fins a quin punt va conèixer alguna de les versions llatines, o quin paper van tenir autors intermediaris en la descoberta del conjunt d'aquests llibres. És factible que Arnau conegués els llibres sobre els animals directament de les traduccions llatines; de fet, Arnau tenia en possessió de l'Ética, i la Metafísica d'Aristòtil i un llibre que podia fer referència al quart llibre dels Meteora ${ }^{76}$. Les citacions que proporciona Arnau dels llibres sobre els animals, i en general de tota l'obra aristotèlica, són poc literals i amb poques variants que permetin discernir si la versió dels llibres provenia de la traducció llatina de Michael Scot o de Guillem de Moerbeke. Això indica que Arnau està més interessat en la doctrina d'Aristòtil que en la seva pròpia referència literal.

Ara bé, aquesta metodologia i els temes que tracta també posen de relleu la possibilitat que Arnau conegués alguna d'aquestes referències per via indirecta a través d'autors intermediaris o tercers. En aquest cas, emperò, no hi ha coincidències amb el contingut d'Aristòtil que proporciona la guia

quod formationem exteriorum membrorum precesserit formatio interiorum, quemadmodum ipsemet verificavit ibidem». Referència a Aristòtil, Historia animalium, VII. 3, 583b13-19.

75. Aristòtil, De historia animalium, VII. 3, 583b1-19.

76. Roc Chabàs. Inventario de los libros, ropas y demás efectos de Arnaldo de Villanueva (pergamino 0.7430 del archivo Metropolitano de Valencia). Revista de Archivos, Bibiotecas y Museos. 1903; 9: 200, núm. 308; Ramon d'Alòs. De la marmessoria d'Arnau de Vilanova. In: Miscel.lània Prat de la Riba, Vol. 1. Barcelona: Institut d'Estudis Catalans; 1923, p. 304. 
d'estudiants d'arts de la universitat de París ${ }^{77}$. Tampoc sembla que les seves referències provinguin d'algun florilegi o recull d'autoritats, a pesar de la coincidència que es troba en l'afirmació sobre la importància del cor en el moviment. Arnau utilitza aquesta referència en el Tractatus de intentione medicorum, un escrit elaborat durant la seva etapa com a docent a la Facultat de Montpeller i ho fa en un ambient idoni per accedir a aquest tipus de reculls. A més, hem de tenir present que moltes de les afirmacions d'Arnau s'inscriuen en un context de discussió. En aquest sentit, no podem menysprear el paper que autors com Galè, Avicenna o altres metges van tenir en l'assimilació d'Aristòtil, sense necessitat de conèixer directament el seu text llatí. Algunes de les afirmacions d'Arnau s'inscriuen en debats mèdics que segueixen Avicenna, com per exemple el principi de generació de l'esperma, una qüestió que havia estat abordada per altres metges, com Gilbert d'Anglaterra. I de fet, en aquest cas tot sembla indicar que Arnau remet als tòpics comuns de les discussions de l'època més que oferir una nova reflexió a partir dels llibres sobre els animals.

Arnau utilitza els llibres sobre els animals d'Aristòtil per descriure processos biològics i fisiològics de l'ésser humà dins làmbit de la medicina, i més concretament en alguns tòpics que caracteritzaven les discussions entre medicina i filosofia natural. Altres metges de la regió italiana com Pietro d'Abano o Taddeo Alderotti també implementaven aquests escrits en el context de les controvèrsies entre metges i filòsofs naturals. Amb aquest conjunt de llibres, Arnau desenvolupa diverses qüestions. Una de les que va tenir més repercussió fou la importància del cor com a centre del moviment, una idea que Arnau reprodueix en més d'una obra. També va utilitzar informació d'Aristòtil relacionada amb la generació i el desenvolupament de l'embrió. En definitiva, Arnau va emprar els llibres sobre els animals d'Aristòtil en el marc d'aquestes discussions per definir els límits d'una nova pràctica mèdica que es fonamentava en elements de la filosofia natural i, per fer-ho, Arnau va utilitzar aquelles observacions i descripcions d'Aristòtil que contribuïen a sustentar-la.

77. Lafleur, Claude. Le «Guide de l'étudiant» d'un maître anonyme de la Faculté des arts de Paris au XIlle siècle. Québec: Université Laval; 1992. 
